\section{Assessing patient adherence to chronic diseases treatment: differentiating between epidemiological and clinical approaches}

\author{
Avaliação da adesão do paciente ao tratamento \\ de doenças crônicas: diferenciando as abordagens \\ epidemiológica e clínica
}

\author{
1 Faculdade de Medicina, \\ Universidade de São Paulo, \\ São Paulo, Brasil. \\ 2 Departamento de Medicina, \\ Universidade Regional de \\ Blumenau, Blumenau, Brasil. \\ 3 Centro de Referência e \\ Treinamento/AIDS, Secretaria \\ Estadual de Saúde de São \\ Paulo, São Paulo, Brasil. \\ Correspondence \\ M. I. B. Nemes \\ Departamento de Medicina \\ Preventiva, Faculdade \\ de Medicina, Universidade \\ de São Paulo. \\ Av. Dr. Arnaldo 455, 2o andar, \\ sala 2172, São Paulo, SP \\ 01246-903, Brasil. \\ mibnemes@usp.br
}

\section{Abstract}

This review discusses the concepts and methods for assessing patient adherence to treatment, as applied to both epidemiological and clinical approaches within real health care practices. For the epidemiological approach, the assessment must be as accurate as possible. Self-reported questionnaires are the most feasible option in most circumstances, but most demonstrate low sensitivity combined with high specificity. We suggest that self-reported outcomes, where feasible, can increase the sensitivity for non-adherence of these questionnaires. In the clinical approach an accurate distinction between adherents and non-adherents is less useful. For the health provider, it is more important to be aware of the particular situation that each patient is currently experiencing with his/her treatment. Self-reported questionnaires applied in clinical settings can help the health provider to form an objective opinion. In any event, the patient-provider dialogue is still the best approach to assess patient adherence as well as to deliver good care.

Patient Compliance; Chronic Disease; Evaluation of Results of Therapeutic Interventions
Maria Ines Battistella Nemes 1

Ernani Tiaraju de Santa Helena 2

Joselita M. M Caraciolo 1,3

Cáritas Relva Basso 1,3

\section{Introduction}

Good outcomes from chronic diseases largely depend on the degree of patient adherence to treatment. Many studies have shown that some degree of non-adherence occurs universally, in rich and poor countries alike, and is even seen in life-threatening diseases 1,2 .

Large variations have been reported in the extent of non-adherence in individual patients and populations. In addition, studies have presented different concepts of adherence as well as different measurements, without necessarily explaining how these criteria interplay.

This is a free review aiming to discuss concepts and methodological approaches for assessing adherence, applied at both epidemiological and clinical contexts within real health care practices. Our motivation to write it was based on discussions we have had in our research group on adherence which bring together epidemiologists and clinicians. We searched the PubMed and SciELO databases to select studies that discuss different concepts and methods for assessing adherence to chronic diseases. Most search results focused on reviews, but original papers were also included. Further references were selected from the bibliographies of cited papers. 


\section{Measuring adherence: different definitions (but same methodology)}

The concepts that are most commonly used are "compliance" and "adherence". Compliance was defined as the extent to which a person's behavior coincides with medical or health recommendations 3 .

This definition became popular in the late 1970s, and was considered to be less judgmental compared with other terms that classified patients as "recalcitrant", "careless" or "irresponsible". The concept led to patients that were not following treatment being considered as a scientific problem which could be potentially studied and addressed ${ }^{4}$. However, many studies have criticized this concept, both for its coercive connotation as well as the fact that it reduces the issue to a matter of patient obedience $5,6,7$.

Adherence was defined as the extent to which a person's behavior corresponds with agreed recommendations from a health care provider 8 .

The notion of adherence proposes an alliance relationship, whereby therapeutic guidance should be agreed upon between patient and health professional, thus recognizing partial autonomy of the patient with regard to how treatment is followed 8 .

Many studies have discussed both notions. This includes some who consider compliance as a dimension of adherence 9 , those who "advocate" one concept or another 10,11, those who use the terms interchangeably 12 , and those who propose new notions attempting to overcome the limitations attributable to both compliance and adherence 13 .

This debate, however, does not seem to have significantly affected empirical studies. Indeed these have frequently employed both terms, irrespective of the methodology used 14 . This "theoretical indifference" appears not to have occurred by chance. Studies measuring adherence are essentially epidemiological studies, in other words, aimed at population contexts. In these settings it is of little importance whether the adherent groups are "obedient" or "autonomous". The key focus is on accurately measuring the number of adherents. After all, the end goal is to understand the problem from an epidemiological point of view, in so far as determining the adherence rate in the group under study. In this context, the title by Baril 15 (p. 13) seems quite fitting: “Observance, adherence, compliance... different words for better therapeutic results".

This discussion takes on a different meaning in a clinical context, as will be discussed. Indeed, we shall seek to discuss some methodological issues involved in getting highest accuracy and greatest explanatory value from studies assessing adherence in epidemiological contexts.

\section{Addressing adherence in epidemiological contexts: seeking better accuracy}

The majority of studies have used an acceptable rate of doses taken/prescribed or even general behavioral patterns of patients in relation to the medication as carelessness/forgetfulness.

Methods that quantify medication taken over a period of time allow for several continuous measurements as well as mean values. However, themajorityofstudies establishacut-offpoint that represents an acceptable limit of non-adherence. The cut-off point is generally based on prior studies which have compared other methods and takes into account the acceptable clinical response for each disease. Thus for hypertension, "adherents" are considered as those that take at least $80 \%$ of prescribed medicines 16 , while for AIDS treatment most studies have adopted 95\% or more 17 .

Different cut-off points obviously lead to different quantitative values of adherence. For example, a study in hypertension which defines adherent patients as those who take at least $80 \%$ of their medication and detect some $70 \%$ of adherence, will report a lower percentage of adherent individuals upon adopting a stricter stance, accepting only those taking $95 \%$ of the prescribed dose 18 .

Questionnaires seeking to estimate patterns of adherence behavior need to establish arbitrary cut-off points in defining non-adherent subjects 19. Depending on the response to one or more questions, an individual shall be categorized as non-adherent, thereby establishing the frequency of non-adherent individuals in a given group.

Patient self-reports through structured interviews are the most used options in observational studies due to their ease of application and low cost. Self-report measures should be assessed on the basis of their validity and electronic monitoring can be used as a reference standard. Pill counting, which is easy to apply and low cost, can also be used as standard although it presents more accuracy problems than electronic monitoring 20.

An important criticism concerning questionnaires used in epidemiological studies regards the conditions under which they are applied. Firstly, there is the issue of why questionnaires focus on undesirable behavior and why patients do not feel at ease answering these within the care facility they attend. Nevertheless, it should 
be recognized that some measures traditionally viewed as more objective, such as manual pill counting or electronic monitoring may also not guarantee reliable results: pills may be discarded and even electronic chips on bottles can be tampered 1,21,22. Therefore a self-report conducted through a well designed questionnaire in a confidential interview has been considered a useful measure of adherence 23,24 .

Moreover many self-reported questionnaires have provided reliable adherence measurements. This has been observed in studies on AIDS 25,26,27, hypertension 28,29 and immunosuppressant therapy 30 .

In addition to obtaining different adherence rates, the correlation amongst the various measures of adherence has frequently been low $31,32,33$. The key differences obtained for each of the adherence measures has led to recommendations for simultaneous use of more than one method in a bid to improve the performance of the final measurement 8,34,35.

Combined measurements should however aim to ascertain simultaneously the several dimensions of adherence, and not solely the percentage of doses taken. In any event, if we accept that adherence is composed of the act, process and effect of adherence, we require measurements which can reflect as accurately as possible these different analytical facets.

A composite adherence score that uses electronic monitoring, pill counts, and patient selfreports 36,37 can assess all these facets but may be not feasible in many settings. For most settings, questionnaires still are the cheapest and most feasible option. Non-threatening and non-judgmental questions are capable of detecting both the act of adhering (through taken/missed doses) and the process (through regular/erratic timing of medication).

The effect of adherence, which is evidently a favorable clinical outcome, warrants further discussion.

Although clinical measures are widely used as indicators of adherence by physicians in clinical contexts 38 , few authors used clinical control as part of the "deciding rule" to consider the individual as adherent in epidemiological study. The classical definitions of adherence used in most studies do not consider clinical outcomes as a component of adherence. In such studies, the clinical outcome is commonly used to establish correlations between levels of adherence and outcome, and to validate the adherence measurement or even establish cut-off points between adherents and non-adherents 16,39.

The use of clinical outcomes as an indirect measurement of adherence is evidently limited by the fact that clinical improvement depends not only on correctly taking medication, but on several other factors. Among them, the most important is the non-response whose distinction from non-adherence is a crucial matter to the clinical approach. From an epidemiological point of view, this distinction is also very important in clinical trials assessing the efficacy of medicines.

However, the chronic disease treatments that are carried out in most health care services establish their average efficacy beforehand. Therefore, from an epidemiological point of view the measure of ratios and means of adherence does not always need to take into account rates of non-response. The association between adherence and mortality rates independently of the response has already been well established for many chronic conditions 40 . Another important focus of epidemiological studies on adherence is the association between adherence rates and the level of quality of health care services 41,42 .

The most important methodological requirement to measures of adherence in epidemiological studies is their accuracy. Some self reported indicators of outcomes can be useful to improve the accuracy of adherence measures.

Blood pressure reading, a simple and easily applied measure, was used in an early study on adherence to treatment in hypertension. Considering non-adherents as those reporting non-adherence and presenting uncontrolled blood pressure, the rate of non-adherence increased from $67.6 \%$ to $79.6 \% 28$.

We have recently developed a self-reported questionnaire to measure adherence to hypertension treatment. The questionnaire contains three questions which sought to assess the three dimensions discussed above. The final non-adherence rate is composed of self reported missed doses (act of adhering), timing of pill consumption (process of adhering) and the presentation of uncontrolled blood pressure (effect of adhering). The rate of non-adherence increased from $17.4 \%$ (for missed doses) to $28.3 \%$ (for timing) and to $30.7 \%$ (for report of uncontrolled arterial pressure). The combined measurement was $47.73 \%$. Using also a combined measurement as a gold standard comprised of pill counting (the act), the Morisky et al. 19 questionnaire (process) and blood pressure measurement (effect), sensitivity was $63 \%$ and the predictive positive value was $91 \% 43$.

Self reported clinical outcome, when feasible, is able to increase sensitivity for non-adherence, i.e. the detection of true non-adherents of the questionnaires used in the epidemiological studies in the usual health care settings. This is an advantage in view of the fact that the major- 
ity of self-reported cases achieve low sensitivity coupled with high specificity (since patients who state they are non-adherent almost always are but not the opposite i.e. patients who state they are adherent may not be in many cases).

On the other hand, improving sensitivity can increase the proportion of false positives, i.e. erroneously considering those who adhere as nonadherents. This can be, however, an additional advantage, since the choice of method should, as well as its validity and reliability, be based on its usefulness in light of the researcher's goals. If, for instance, we intend to use adherence ratios as indicators of the quality of care in health services (or the effectiveness of an intervention), overestimating the number of non-adherents (through false-positive individuals) seems appropriate. In any event, the main aim in this situation is to identify the greatest number of non-adherents possible for subsequent targeting by the health care team.

The studies on adherence within the epidemiological contexts contribute towards the devising of policies and achieving more effective managerial and clinical practices. The quality of this contribution depends on the quality of methodological approaches. However, this also depends on the correct interpretation and incorporation of findings into practice.

Studies of adherence to AIDS antiretroviral treatment in Brazil, for instance, have shown that low schooling and missed follow-up are associated with greater odds of non-adherence 42,43 . The results led to strong recommendations to AIDS related health services for the organization of delivering care which prioritizes those groups, providing for instance, swift medical care to those missing appointments, or special activities (such as groups, home visits and so forth) for those with low schooling.

It should be noted, however, that the associations found refer to groups with greater odds of non-adherence, not necessarily implying that individuals belonging to these groups are necessarily non-adherents. Creating special flowcharts for these groups cannot be a substitute for individual care and, most importantly, should not imply discriminatory attitudes to those erroneously called "high risk for non-adherence", as has unfortunately been seen in some contexts 44,45 . In contrast, this entails offering special care to those who are most vulnerable, precisely in a bid to actively foster equity. This discussion is however more relevant for the clinical context.

\section{Addressing adherence in the clinical context: seeking better care}

Whereas epidemiological studies seek to differentiate accurately between adherent and nonadherent groups, this division is meaningless in the realm of individual care. In this context clinical control is the most often used "measure" of adherence employed by physicians 46,47 .

Indeed, if the patient is doing well, all is well. Thus, for instance, in a strategy of "intelligent non-adherence" patients rightly conclude they may achieve the same therapeutic success while reducing the medication prescribed, a fact long acknowledged amongst people with hypertension 48,49 . Even recent AIDS treatment studies have shown that for some antiretroviral regimens there is no need for "almost perfect" adherence as early studies had suggested 50 .

For health professionals, chiefly the physician, it is important to assess patient adherence when clinical outcome is not as expected. In this case, the professional's impression based on questioning the patient is widely used. However, the physician's opinion as a method of measuring adherence is classically criticized. Many studies have shown high values of disagreement amongst adherence rates assessed by professional and those self-reported by patients and by electronic monitoring 51,52. These studies however, refer to differences amongst adherence ratios of groups. For this reason, studies measuring adherence in the epidemiological context rarely use clinicians' opinions as a method of measurement. When used, it is only considered as part of composed scales of adherence (once it is recognized that the clinicians' assessments of their patients' adherence are strongly based on the clinical and laboratorial results) 49,50.

Individual care, on the other hand, clearly cannot override medical opinion, for risk of undermining the technical basis of medical work, grounded in the autonomy of reaching judgments and taking decisions also based on the individual meeting with the patient 53 . In other words, it is impossible for the physician not to base their decision on the impression they acquire from contact with the patient.

Obviously, the inherent subjectivity of the medical decision can be balanced through additional instruments. This highlights when it is necessary to differentiate between not-enough adherence and non-response.

The usual "objective" adherence measures (such as manual or electronic pill count) may be used in some clinical settings. However all of them have well-known limits of reliability and feasibility. Most importantly they can be counter- 
productive since the patients may perceive them as intrusive and suggestive of a lack of trust from the provider 12,54,55.

In the clinical context of adherence measures must be practical, inexpensive and suitable in the context of the patient-provider relationship. Therefore questionnaires (whose reliability and validity had been tested in epidemiological studies) can be helpful in increasing the objectivity of the physician's decisions 56,57 .

However, these questionnaires should be viewed as auxiliary instruments and be used carefully. To repeatedly measure a patient's adherence may have some undesirable effects on the patient-provider relationship as well as reinforce the "white coat adherence" effect.

In spite of these limits, it is essential for the physician to be aware of patient adherence. Together with the clinical parameters, adherence is important to enable therapeutic modifications. The exact dose of medication needed to achieve the desired clinical outcome has only been well established for a few diseases. In the majority of cases, the dose required must be adjusted for each patient. Therefore in most cases the physician has to know the patient's adherence, and not "to figure out" whether he/she is "adherent" or "non-adherent" but rather to be aware of the particular situation each patient is currently experiencing with the prescribed treatment. It is also very important to counsel patients in establishing routines of use, particularly important for chronic diseases.

However no adherence "measure" is able to render spoken patient reports objective to the point of making them totally transparent to the physician. This is only possible if the patienthealth team relationship is based on mutual trust and truthful dialogue.

It is this very issue that represents the greatest promise for discussion on the ideas of compliance and adherence. The notion of adherence has attempted to bring into focus the patient's point of view with regard to treatment plans. However, while for advocates of "adherence" the notion represented an evolution in the meaning of considering the autonomy of the patient, more radical propositions argue that there is little difference between adherence and compliance.

Several proposals have already criticized the notions of compliance and adherence, proposing their replacement by ideas which better reflect the need to value the autonomy of the patient in relation to the treatment. Examples include notions of collaboration 58 , autonomy motivation 59 and empowerment 60 .

By the same token, the Royal Pharmaceutical Society of Great Britain 61 suggested substituting both terms for the notion of concordance which attempts to express the process of prescribing/ taking medicines as a therapeutic partnership between physician and patient.

The notion of concordance has become frequently used in studies from the United Kingdom. Its definition has changed over time from one which focused on the consultation process, to a broader notion which ranges from prescribing communication to patient support in medicine taking ${ }^{62}$. Recent studies have pointed out that concordance is synonymous with neither compliance nor adherence. For them, the notion does not refer to patient's medicinetaking behavior, but rather the provider-patient interaction 63 .

With regard to different theoretical origins, all of these new conceptual approaches and particularly the notion of concordance have been sought to acknowledge actively the presence of another party - the patient - in the health care arena. Therefore they highlight the crucial role of communication in the clinical context.

Concerning this point a fruitful proposition has been disseminated in Brazil. Based on the philosophical concept of Care, it proposes that health providers revisit their attitudes and conceptions, that are oriented in a strictly biomedical sense $64,65,66,67,68$. It argues that those patients' needs beyond those strictly related to clinical control are not effectively incorporated into health care process, and continue as barriers to adherence 69 . Addressing the issue Ayres 67 (p. 72-3) argues: "In a consultation, in attentive listening, yet oriented in a purely technical sense, elements may arise from patients which are deemed as the non-comprehension of instructions (...), or disregard for health. In listening (...) which does not have technical success as a strict goal of the dialogue, the same elements may appear as a conflict of values in adopting guidance (...), practical obstacles to observance of the prescription (...) or simply a mismatch between what [the patient] is looking for [in the health service] and what is being offered".

This notion of care understands that those "nontechnical" dimensions have to be actively considered by the health care provider (and not be only informally responded to by means of providers' personal initiatives and compassionate feelings). It argues that that the technical success of the treatment depends on a "practical success" i.e. the capacity of the health care in focusing, beyond the clinical outcome, on the aspirations of the patients relating to health, but also and especially to life more broadly. In this sense, it proposes that care must include a negotiation of the best possible outcome given 
the patient's project of life and well-being at the time 65,67,68.

It is almost intuitive to realize that the good health provider-patient dialogue is a basic underlying condition for both "concordance" and "care" notions. The notion of care however seems more useful in helping to understand the issue of adherence to treatment in the clinical context through criticizing the understanding of treatment as being restricted to an instrumental relationship between that which holds the best technique (the physician) and that which is the object of this technique (the "patient").

It seems however, that the best potential of this notion of care lies in the recuperation of the human side of health work, without diminishing the weight of its technical dimension. Evidently, work in health shall always have a technical goal: we work towards ensuring patients follow treatment and improve their health. However, this aim cannot be artificially separated from the human relationship established in a bid to achieve this, nor can the price at which this is achieved be ignored.

Epidemiological research on taking medicines can work with different definitions of the issue. The usefulness of their contributions predominately lies in their methodological coherence and accuracy. In the clinical context, recognizing adherence as a dynamic phenomenon 70 and accepting that all chronic disease patients have their moments of non-adherence ${ }^{71}$ appears to be the best approach to care. Moreover, accepting patient behavior in our relationships with patients is also needed. As Bernardini 72 (p. 227) says "Would it help to adopt Fred Rogers' theme, 'I like you just the way you are', to improve relationships with patients who would then be more likely to comply?".

\section{Resumo}

Esta revisão discute conceitos e métodos de avaliação da adesão do paciente ao tratamento de saúde, aplicáveis para a abordagem epidemiológica e para a abordagem clínica. Na abordagem epidemiológica, a avaliação deve ter a melhor acurácia possível. Os questionários de auto-relato são a opção mais viável na maioria dos contextos. Entretanto, a maior parte dos questionários apresenta baixa sensibilidade aliada a alta especificidade. Sugere-se que o desfecho clínico auto-relatado, quando factível, é capaz de aumentar a sensibilidade desses questionários. Para a abordagem clínica, uma acurada discriminação entre aderentes $e$ não aderentes é pouco útil. Para o profissional de saúde, é mais importante conhecer a situação particular pela qual o paciente está, no momento, passando com seu tratamento. Questionários de auto-relato aplicados no contexto clínico podem auxiliar a melhorar a objetividade da opinião do profissional. Em qualquer caso, contudo, o diálogo paciente-profissional é ainda a melhor abordagem para avaliar a adesão, assim como para prover um bom cuidado.

Cooperação do Paciente; Doença Crônica; Avaliação de Resultado de Intervenções Terapêuticas

\section{Contributors}

M. I. B. Nemes, E. T. S. Helena, J. M. M. Caraciolo and C. R. Basso were responsible for study conception, design, data collection and writing up of the final article. 


\section{References}

1. Wright E.C. Noncompliance - or how many aunts has Matilda? Lancet 1993; 342:909-13.

2. Haynes RB, McKibbon KA, Kanani R. Systematic review of randomised trials of interventions to assist patients to follow prescriptions for medications. Lancet 1996; 348:383-6.

3. Haynes RB. Introduction. In: Haynes RB, Taylor W, Sackett DL, editors. Compliance in health care. 2nd Ed. Baltimore: John Hopkins University Press; 1981. p. 1-7.

4. Lutfey KE, Wishner WJ. Beyond "compliance" is "adherence": improving the prospect of diabetes care. Diabetes Care 1999; 22:635-9.

5. Conrad P. The meaning of medication: another look at compliance. Soc Sci Med 1985; 20:29-37.

6. Dowell J, Hudson H. A qualitative study of medication-taking behaviour in primary care. Fam Pract 1997; 14:369-75.

7. McNabb WL. Adherence in diabetes: can we define it and can we measure it? Diabetes Care 1997; 20:215-8.

8. World Health Organization. Adherence to longterm therapies: evidence for action. Geneva: World Health Organization; 2003.

9. Hughes CM. Medication non-adherence in the elderly: how big is the problem? Drugs Aging 2004; 21:793-811.

10. Dobkin JF. You say "adherence”, I say "compliance”. Infect Med 1998; 15:65.

11. Lowes R. Patient-centered care for better patient adherence. Fam Pract Manag 1998; 5:46-7.

12. Krousel-Wood M, Thomas S, Muntner P, Morisky D. Medication adherence: a key factor in achieving blood pressure control and good clinical outcomes in hypertensive patients. Curr Opin Cardiol 2004; 19:357-62.

13. Chatterjee JS. From compliance to concordance in diabetes. J Med Ethics 2006; 32:507-10.

14. Vermeire E, Hearnshaw H, van Royen P, Denekens J. Patient adherence to treatment: three decades of research: a comprehensive review. J Clin Pharm Ther 2001; 26:331-42.

15. Baril L. Observance, adherence, compliance... different words for better therapeutic results. Presse Med 1998; 27 Suppl 5:13-4.

16. Haynes RB, Gibson ES, Taylor DW, Bernholz CD, Sackett DL. Process versus outcome in hypertension: a positive result. Circulation 1982; 65:28-33.

17. Lucas GM, Wu AW, Cheever LW. Adherence to antiretroviral therapy: an update of current concepts. Curr HIV/AIDS Rep 2004; 1:172-80.

18. Svarstad BL, Chewning BA, Sleath BL, Claesson C. The brief medication questionnaire: a tool for screening patient adherence and barriers to adherence. Patient Educ Couns 1999; 37:113-24.

19. Morisky DE, Green LW, Levine DM. Concurrent and predictive validity of a self-reported measure of medication adherence. Med Care 1986; 24: 67-74.

20. Cumings KM, Kirsht JP, Becker MH, Levin NW. Construct validity of the free methods for measuring patient compliance. Health Serv Res 1984; 19:103-16.
21. Meredith PA. Enhancing patient's compliance. BM 1998; 316:393-4.

22. Murri R, Amassari A, De Luca A, Cingolani A, Antinori A. Definition and measurement of adherence to antiretroviral drugs in HIV-1-infected patients. Lancet 1999; 353:1974.

23. Butler JA, Peveler RC, Roderick P, Horne R, Mason JC. Measuring compliance with drug regimens after renal transplantation: comparison of self-report and clinician rating with electronic monitoring. Transplantation 2004; 77:786-9.

24. Simoni JM, Kurth AE, Pearson CR, Pantalone DW, Merrill JO, Frick PA. Self-report measures of antiretroviral therapy adherence: a review with recommendations for HIV research and clinical management. AIDS Behav 2006; 10:227-45.

25. Chesney MA, Ickovics JR, Chambers DB, Gifford AL, Neidig J, Zwickl B, et al. Self-reported adherence to antiretroviral medications among participants in HIV clinical trials: the AACTG adherence instruments. Patient Care Committee \& Adherence Working Group of the Outcomes Committee of the Adult AIDS Clinical Trials Group (AACTG). AIDS Care 2000; 12:255-66.

26. Duran S, Solas C, Spire B, Carrieri MP, Fuzibet JG, Costagliola D, et al. "Do HIV-infected injecting drug users over-report adherence to highly active antiretroviral therapy?" A comparision between patients' self reports and serum protease inhibitor concentrations in the French Manif 2000 cohort study. AIDS 2001; 15:1075-7.

27. Gifford AL, Bormann JE, Shively MJ, Wright BC, Richman DD, Bozzette SA. Predictors of self-reported adherence and plasma HIV concentrations in patients on multidrug antiretroviral regimens. J Acquir Immune Defic Syndr 2000; 23:386-95.

28. Inui TS, Carter WB, Pecoraro RE. Screening for non-compliance among patients with hypertension: is self-report the best available measure? Med Care 1981; 19:1061-4.

29. Toyoshima H, Takahashi K, Akera T. The impact of side effects on hypertension management: a Japanese survey. Clin Ther 1997; 19:1458-69.

30. Chisholm MA, Lance CE, Williamson GM, Mulloy LL. Development and validation of the immunosuppressant therapy adherence instrument (ITAS) Patient Educ Couns 2005; 59:13-20.

31. Choo PW, Rand CS, Inui TS, Lee ML, Cain E, Cordeiro-Breault M, et al. Validation of patients reports automated pharmacy records and pill counts with electronic monitoring to adherence to antihypertensive therapy. Med Care 1999; 37:846-57.

32. Rand CS. Measuring adherence with therapy for chronic diseases: implications for the treatment of heterozygous familial hypercholesterolemia. Am J Cardiol 1993; 72:68D-74D.

33. Wagner GJ. Predictors of antiretroviral adherence as measured by self-report, electronic monitoring, and medication diaries. AIDS Patient Care STDS 2002; 16:599-608.

34. Berg KM, Aransten JK. Practical and conceptual challenges in measuring antiretroviral adherence. J Acquir Immune Defic Syndr 2006; 43 Suppl 1: S79-87. 
35. DiMatteo MR, Giordani PJ, Lepper HS, Croghan TW. Patient adherence and medical treatment outcomes: a meta-analysis. Med Care 2002; 40: 794-811.

36. Liu H, Golin CE, Miller LG, Hays RD, Beck CK, Sanandaji S, et al. A comparison study of multiple measures of adherence to HIV protease inhibitors. Ann Intern Med 2001; 134:968-77.

37. Paterson DL, Potoski B, Capitano B. Measurement of adherence to antiretroviral medications. J Acquir Immune Defic Syndr 2002; 31 Suppl 3:S103-6.

38. Rodondi N, Peng T, Karter AJ, Bauer DC, Vittinghoff E, Tang S, et al. Therapy modifications in response to poorly controlled hypertension, dyslipidemia, and diabetes mellitus. Ann Intern Med 2006; 144:475-84

39. Paterson DL, Swindells S, Mohr J, Brester M, Vergis $\mathrm{EN}$, Squier C, et al. Adherence to protease inhibitor therapy and outcomes in patients with HIV infection. Ann Intern Med 2000; 133:21-30.

40. Simpson SH, Eurich DT, Majumdar SR, Padwal RS, Tsuyuki RT, Varney J. A meta-analysis of the association between adherence to drug therapy and mortality. BMJ 2006; 333:1-6.

41. Nemes MIB, organizador. Avaliação da aderência ao tratamento por anti-retrovirais em usuários de ambulatórios do sistema público de assistência à AIDS no Estado de São Paulo: Coordenação Nacional de DST/AIDS. (Série Avaliação, 1). http://www. aids.gov.br (accessed on 10/Jun/2008).

42. Nemes MIB, Carvalho HB, Souza MFMS. Antiretroviral therapy adherence in Brazil. AIDS 2004; 18 Suppl 3:S15-20.

43. Helena ETS, Nemes MIB, Eluf-Neto J. Development and validation of a multidimensional questionnaire to measure adherence to medicines. Rev Saúde Pública 2008; 42:764-7.

44. Mesquita F, Doneda D, Gandolfi D, Nemes MI, Andrade T, Bueno R, et al. Brazilian response to the HIV/AIDS epidemic among injecting drug users. Clin Infect Dis 2003; 37 Suppl 5:S382-5.

45. Nemes MIB, Beaudoin J, Conway S, Kivumbi GW, Skjelmerud A, Vogel U. Evaluation of WHO's contribution to "3 by 5": main report. Geneva: World Health Organization; 2006.

46. Parker CS, Chen Z, Price M, Gross R, Metlay JP, Christie JD, et al. Adherence to warfarin assessed by electronic pill caps, clinician assessment, and patient reports: results from the IN-RANGE study. J Gen Intern Med 2007; 22:1254-9.

47. Wagner JH, Justice AC, Chesney M, Sinclair G, Weissman S, Rodriguez-Barradas M, et al. Patientand provider-reported adherence: toward a clinically useful approach to measuring antiretroviral adherence. J Clin Epidemiol 2001; 54:S91-8.

48. Steiner JF, Fihn SD, Blair B, Inui TS. Appropriate reductions in compliance among well-controlled hypertensive patients. J Clin Epidemiol 1991; 44:1361-71.

49. Wagner EH, Truesdale Jr. RA, Warner JT. Compliance, treatment practices and blood pressure control: community and survey findings. J Chronic Dis 1981; 34:519-25.

50. Bangsberg DR, Moss AR, Deeks SG. Paradoxes of adherence and drug resistance to HIV antiretroviral therapy. J Antimicrob Chemother 2004; 53:696-9.
51. DiMatteo MR. Variations in patients adherence to medical recommendations. Med Care 2004; 42:200-9.

52. Miller LG, Hays RD. Adherence to combination antiretroviral therapy: synthesis of the literature and clinical implications. AIDS Read 2000; 10:177-85.

53. Schraiber LB. No encontro da técnica com a ética: o exercício de julgar e decidir no cotidiano do trabalho em medicina. Interface Comun Saúde Educ 1997; 1:123-38.

54. Leite SN, Vasconcellos MPC. Adesão à terapêutica medicamentosa: elementos para a discussão de conceitos e pressupostos adotados na literatura. Ciênc Saúde Coletiva 2003; 8:775-82.

55. Berg KM, Arnsten JH. Practical and conceptual challenges in measuring antiretroviral adherence. J Acquir Immune Defic Syndr 2006; 43 Suppl 1: S79-87.

56. MacLaughlin EJ, Raehl CL, Treadway AK, Sterling TL, Zoller DP, Bond CA. Assessing medication adherence in the elderly: which tools to use in clinical practice? Drugs Aging 2005; 22:231-55.

57. Zeller A, Schroeder K, Peters TJ. An adherence selfreport questionnaire facilitated the differentiation between nonadherence and nonresponse to antihypertensive treatment. J Clin Epidemiol 2008; 61:282-8.

58. Moore KN. Compliance or collaboration? The meaning for the patient. Nurs Ethics 1995; 2:71-7.

59. Williams GC, Rodin GC, Ryan RM, Grolnick WS, Deci EL. Autonomous regulation and long-term medication adherence in adult outpatients. Health Psychol 1998; 17:269-76.

60. Feste C, Anderson RM. Empowerment: from philosophy to practice. Patient Educ Couns 1995; 26:139-44.

61. Royal Pharmaceutical Society of Great Britain. From compliance to concordance: towards shared goals in medicine taking. London: Royal Pharmaceutical Society of Great Britain; 1997.

62. Horne R, Weinman J, Barber N, Elliott R, Morgan M, Cribb A, et al. Concordance, adherence and compliance in medicine taking. Report for the National Co-ordinating Centre for NHS Service Delivery and Organisation R \& D (NCCSDO). London: National Co-ordinating Centre for NHS Service Delivery and Organisation Research \& Development; 2005.

63. Bell JS, Airaksinen MS, Lyles A, Chen TF, Aslani P. Concordance is not synonymous with compliance or adherence. Br J Clin Pharmacol 2007; 64:710-1.

64. Ayres JRCM. Sujeito, intersubjetividade e práticas de saúde. Ciênc Saúde Coletiva 2001; 6:63-72.

65 Ayres JRCM. O cuidado, os modos de ser (do) humano e as práticas de saúde. Saúde Soc 2004; 13:16-29.

66. Ayres JRCM. Cuidado e reconstrução das práticas de saúde. Interface Comun Saúde Educ 2004; 8:73-91.

67. Ayres JRCM. Cuidado e humanização das práticas de saúde. In: Deslandes SF, organizador. Humanização dos cuidados em saúde: conceitos, dilemas e práticas. Rio de Janeiro: Editora Fiocruz; 2006. p. 49-84.

68. Ayres JRCM. Uma concepção hermenêutica de saúde. Physis (Rio J.) 2007; 17:43-62. 
69. Oliveira LA, Landroni MAS, Silva NEK, Ayres JRCM. Humanização e cuidado: a experiência da equipe de um serviço de DST/AIDS no município de São Paulo. Ciênc Saúde Coletiva 2005; 10:689-98.

70. Vervoort SC, Borleffs JC, Hoepelman AI, Grypdonck $\mathrm{MH}$. Adherence in antiretroviral therapy: a review of qualitative studies. AIDS 2007; 21:271-81.
71. Melchior R, Nemes MIB, Alencar TMD, Buchalla CM. Challenges of treatment adherence by people living with HIV/AIDS in Brazil. Rev Saúde Pública 2007; 41 Suppl 2:87-93.

72. Bernardini J. Ethical issues of compliance/adherence in the treatment of hypertension. Adv Chronic Kidney Dis 2004; 11:222-7.

Submitted on 22/Jan/2009

Final version resubmitted on 06/May/2009

Approved on 18/May/2009 